\title{
Nontransferable utility bankruptcy games
}

\section{Arantza Estévez-Fernández ${ }^{1}$ (D) Peter Borm² P. Mloria Fiestras-Janeiro $^{3}$}

Received: 27 August 2018 / Accepted: 12 July 2019 / Published online: 26 August 2019

(c) The Author(s) 2019

\begin{abstract}
In this paper, we analyze bankruptcy problems with nontransferable utility (NTU) from a game theoretical perspective by redefining corresponding NTU-bankruptcy games in a tailor-made way. It is shown that NTU-bankruptcy games are both coalition-merge convex and ordinally convex. Generalizing the notions of core cover and compromise stability for transferable utility (TU) games to NTU-games, we also show that each NTU-bankruptcy game is compromise stable. Thus, NTU-bankruptcy games are shown to retain the two characterizing properties of TU-bankruptcy games: convexity and compromise stability. As a first example of a game theoretical NTU-bankruptcy rule, we analyze the adjusted proportional rule and show that this rule corresponds to the compromise value of NTU-bankruptcy games.
\end{abstract}

Keywords NTU-bankruptcy problem · NTU-bankruptcy game $\cdot$ Coalition-merge convexity $\cdot$ Ordinal convexity $\cdot$ Compromise stability $\cdot$ Adjusted proportional rule

Mathematics Subject Classification 91A12 · 91A40

\section{Introduction}

In a (TU-)bankruptcy problem there is a group of agents with legal monetary claims over an estate, which is not large enough to satisfy the total claim. The question is how to allocate the estate among the agents following two basic principles: first, the whole

M. G. Fiestras-Janeiro acknowledges the financial support of Ministerio de Ciencia e Innovación through project MTM2011-27731-C03.

$凶 \quad$ Arantza Estévez-Fernández

arantza.estevezfernandez@vu.nl

1 Department of Econometrics and Operations Research, Tinbergen Institute, Vrije Universiteit Amsterdam, De Boelelaan 1105, 1081 HV Amsterdam, The Netherlands

2 Department of Econometrics and Operations Research, CentER, Tilburg University, P.O. Box 90153, 5000 LE Tilburg, The Netherlands

3 Departamento de Estatística e Investigación Operativa, Universidade de Vigo, Vigo, Spain 
estate has to be allocated (efficiency); second, no agent should get neither more than his claim, nor a negative amount, that is no agent should pay a fine (boundedness). Bankruptcy problems were first analyzed in a game theoretical framework in O'Neill (1982). O'Neill (1982) defines associated bankruptcy games and shows that these are convex games; Aumann and Maschler (1985) propose the Talmud rule as a solution to bankruptcy problems and show that this rule corresponds to the nucleolus of the associated bankruptcy game; Curiel et al. (1987) show that the (nonempty) core and the core cover of bankruptcy games coincide. In the (later) terminology of Quant et al. (2005), this means that bankruptcy games are compromise stable. Moreover, Curiel et al. (1987) show that the compromise value of bankruptcy games can be interpreted as an adjusted proportional rule for the underlying bankruptcy problem. Quant et al. (2005) show that the class of bankruptcy games is the only class of games that satisfies both convexity and compromise stability, up to $S$-equivalence. For a survey on TUbankruptcy, we refer to Thomson (2003) with an update in Thomson (2015).

In this paper, we investigate bankruptcy problems with nontransferable utility, in short NTU-bankruptcy problems, which are a generalization of bankruptcy problems. An NTU-bankruptcy problem consists, first of all, of a set of agents $N$ who each claim an individual level of utility over an estate. The corresponding vector of utility claims is summarized by $c \in \mathbb{R}_{+}^{N}$. Secondly, an NTU-bankruptcy problem specifies the estate set $E$ of vectors of attainable utility with, typically, $c \notin E$. Although formally in a different setting, Chun and Thomson (1992) is one of the first papers that relates to NTU-bankruptcy problems. Orshan et al. (2003) are the first to analyze NTUbankruptcy problems in a game theoretical framework. They associate an NTU-game to an NTU-bankruptcy problem and show that the intersection of the core and the bilateral consistent prekernel of such a game is nonempty. However, they provide an example which illustrates that their game need not be superadditive and, therefore, not ordinally convex. The reason for this is twofold: first, the value of a coalition may contain payoff vectors assigning a level of utility to a member of the coalition which exceeds his claim; second, the value of a coalition may contain elements that are not in the comprehensive hull of the set $E$. This, in our view, departs from the original idea in O'Neill (1982), where the value of a coalition is defined taking into account that the estate is going to be exactly distributed among the agents following the two basic principles of efficiency and boundedness. Recently, Dietzenbacher (2018) has analyzed NTU-bankruptcy problems using a different NTU-modeling approach, showing that the core of this alternative game coincides with the core cover and the reasonable set. A different class of bankruptcy problems where full transferability is not allowed is that of integer bankruptcy problems as introduced and analyzed in Herrero and Martínez (2008). Here, the estate can only be allocated in integer units and the claims are also integer values. Recently, Fragnelli et al. (2014) study integer bankruptcy problems with non-integer claims with follow-ups in Fragnelli et al. (2016) and Fragnelli and Gastaldi (2017).

This paper redefines NTU-bankruptcy games, staying in line with the idea of O'Neill (1982). It turns out that this type of NTU-bankruptcy games does satisfy ordinal convexity (cf. Vilkov 1977) together with coalition-merge convexity (cf. Hendrickx et al. 2002). As a direct consequence of being coalition-merge convex, NTU-bankruptcy games are also marginal convex (cf. Hendrickx et al. 2002) and reasonable stable (cf. 
Dietzenbacher 2018). Moreover, inspired by Tijs and Lipperts (1982) and Borm et al. (1992), we introduce the core cover for NTU-games. In line with Estévez-Fernández et al. (2012), we show that the core cover of a compromise-admissible NTU-game can be obtained as the translation of the core cover of an associated NTU-bankruptcy game. Following Quant et al. (2005), we define compromise-stable NTU-games as those NTU-games with nonempty core for which the core and the core cover coincide. We show that NTU-bankruptcy games are compromise stable. Therefore, the characterizing properties of convexity and compromise stability for TU-bankruptcy games carry over to NTU-bankruptcy games. The game theoretical framework for NTUbankruptcy problems also enables the analysis of game theoretical NTU-bankruptcy rules. As an example, we characterize the NTU-compromise value as defined in Borm et al. (1992) for bankruptcy games as an adjusted proportional rule.

Our study of NTU-bankruptcy games contributes to a better understanding of the rather intricate model of NTU-games. Although there is a broad literature on NTUgames, there is still a need to better develop and comprehend this important field. As a further illustration of the lack of a solid and comprehensive development of the theory of NTU-games, we refer to the groundbreaking work of Predtetchinski and Herings (2004), Vidal-Puga (2008), and Csóka et al. (2011).

The paper is structured as follows. Section 2 provides notions used throughout the paper. In Sect. 3, we introduce NTU-bankruptcy problems and NTU-games, discuss the requirements that we impose, and redefine NTU-bankruptcy games. Section 4 analyzes the notions of convexity and compromise stability for general NTU-games. Section 5 provides our main results: NTU-bankruptcy games are ordinally convex, coalitionmerge convex, and compromise stable. Section 6 characterizes the compromise value of NTU-bankruptcy games as an adjusted proportional bankruptcy rule.

\section{Preliminaries}

Let $N$ be a finite set, let $x, y \in \mathbb{R}^{N}$, and $S \in 2^{N} \backslash\{\emptyset\}$. We denote $x_{S}=\left(x_{i}\right)_{i \in S}$, $x_{S} \geq y_{S}$ if $x_{i} \geq y_{i}$ for every $i \in S$, and $x_{S}>y_{S}$ if $x_{i}>y_{i}$ for every $i \in S$. Let $U \subset \mathbb{R}^{S}$. We denote by $\partial U$ the boundary of $U$. We say that $U$ is comprehensive if for all $a, b \in \mathbb{R}^{S}$ with $a \in U$ and $b \leq a$, it follows that $b \in U$. By comp $(U)$ we denote the comprehensive hull of $U$. The set of weakly Pareto elements of $U, \operatorname{WP}(U)$, is defined by

$$
\mathrm{WP}(U)=\{x \in U: \text { there is no } y \in U \text { such that } y>x\} \text {. }
$$

Related to the set of weakly Pareto elements, the set of (strictly) dominated elements of $U, \operatorname{Dom}(U)$, is defined by

$$
\operatorname{Dom}(U)=\left\{x \in \mathbb{R}^{S}: \text { there is } y \in U \text { such that } y>x\right\} \text {. }
$$




\section{Modeling NTU-bankruptcy problems}

In this section, we introduce NTU-bankruptcy problems, discuss the approach of Orshan et al. (2003) to model them as an NTU-game, and propose an alternative NTU-bankruptcy game.

In a TU-bankruptcy problem, there is a group of agents that have claims over an estate which is not high enough to satisfy all claims. Formally, a bankruptcy problem is a tuple $(N, e, c)$ where $N$ is the set of agents, $e \in \mathbb{R}_{+}$is the available estate, and $c \in \mathbb{R}_{+}^{N}$ is the vector of claims, with ${ }^{1} \sum_{i \in N} c_{i} \geq e$.

NTU-bankruptcy problems generalize bankruptcy problems. Our definition of NTU-bankruptcy problems is inspired by Chun and Thomson (1992). An NTUbankruptcy problem is a tuple $(N, E, c)$ where $N$ is a finite set of agents while $E \subset \mathbb{R}_{+}^{N}$ and $c \in \mathbb{R}_{+}^{N}$ are such that the following five conditions are satisfied:

(E1) $E$ is closed, convex, and $E \cap \mathbb{R}_{++}^{N} \neq \emptyset$,

(E2) there exist $p \in \mathbb{R}_{++}^{N}$ and $r \in \mathbb{R}$ such that for all $x \in E, \sum_{i \in N} p_{i} x_{i} \leq r$,

(E3) $E=\operatorname{comp}(E) \cap \mathbb{R}_{+}^{N}$,

(E4) if $x, y \in \mathrm{WP}(E) \cap \mathbb{R}_{+}^{N}$ and $x \geq y$, then, $x=y$,

(E5) $c \notin \operatorname{int}(\operatorname{comp}(E)) .^{2}$

Condition (E2) implies that $E$ is bounded and condition (E4) is a non-levelness property which is not required in Chun and Thomson (1992). It imposes that the weak Pareto boundary of $E$ does not have segments parallel to a coordinate hyperplane. Notice that $\operatorname{WP}(E)$ is the closure of $\partial E \cap \mathbb{R}_{++}^{N}$.

As pointed out in Orshan et al. (2003), $E$ can be interpreted to represent the set of utility vectors that the agents may achieve by means of efficient allocations of the available estate and $c$ represents the utility levels claimed by the agents.

TU-bankruptcy problems have been studied in the literature along two different lines. One of the lines is the axiomatic study of bankruptcy rules, the other is the analysis of bankruptcy problems from a game theoretical perspective. This article will focus on the second line of research for NTU-bankruptcy problems.

We first recall the definitions of TU-bankruptcy games and of NTU-games. TUbankruptcy games were first analyzed in O'Neill (1982). A transferable utility game (TU-game) is given by a pair $(N, v)$ where $N$ is the finite set of agents (or players) and $v: 2^{N} \rightarrow \mathbb{R}$ is a characteristic function satisfying $v(\emptyset)=0$. Given a bankruptcy problem, $(N, e, c)$, the associated bankruptcy game, $\left(N, v_{e, c}\right)$, is defined by $v_{e, c}(S)=$ $\max \left\{0, e-\sum_{i \in N \backslash S} c_{i}\right\}$ for every $S \subset N$. The interpretation of the coalitional value $v_{e, c}(S)$ is as follows. Coalition $S$ decides to leave the negotiations before the sharing of the estate $e$. This implies that if the total claim of the players in $N \backslash S$ exceeds $e$, then, $S$ leaves with nothing and the agents in $N \backslash S$ continue the negotiations for $e$. Otherwise, each agent in $N \backslash S$ gets exactly his claim, $c_{i}$, and the agents in $S$ start negotiations for the remaining of the estate, $e-\sum_{i \in N \backslash S} c_{i}$, following the two basic principles of efficiency (exactly $e-\sum_{i \in N \backslash S} c_{i}$ is allocated) and boundedness (no agent in $S$ gets neither more than his claim, nor a negative amount). The study of bankruptcy games

\footnotetext{
${ }^{1}$ For technical reasons, it is imposed that $\sum_{i \in N} c_{i} \geq e$ instead of $\sum_{i \in N} c_{i}>e$.

2 For technical reasons, it is imposed that $c \notin \operatorname{int}(\operatorname{comp}(E))$ instead of $c \notin E$.
} 
and game theoretical bankruptcy rules has been further developed in Aumann and Maschler (1985) and Curiel et al. (1987).

Following Peleg and Sudhölter (2007), a nontransferable utility game (NTU-game) is a pair $(N, V)$ where $N$ is a finite set of players and $V$ is a set valued function that assigns to each $S \subset N$ a set $V(S) \subset \mathbb{R}^{S}$ of attainable payoff vectors satisfying

(1) $V(\emptyset)=\emptyset$;

(2) for every $S \in 2^{N} \backslash\{\emptyset\}, V(S)$ is nonempty, closed, and comprehensive;

(3) for every $S \in 2^{N} \backslash\{\emptyset\}$, the set $V(S) \cap\left(\{x\}+\mathbb{R}_{+}^{S}\right)$ is bounded for every $x \in \mathbb{R}^{S}$.

From now on, we denote

$$
v(i)=\max \left\{z_{i}: z \in V(\{i\})\right\}
$$

for every $i \in N$. Notice that $v(i)$ is well defined since $V(\{i\})$ is nonempty and closed by condition (2) and $V(\{i\})$ is bounded from above by (3).

An NTU-game $(N, V)$ is $N$-convex if $V(N)$ is convex, and it is non-leveled ${ }^{3}$ if $x, y \in \partial V(N)$ with $y_{i} \geq v(i)$ for every $i \in N$ and $x \geq y$ implies $x=y$.

Orshan et al. (2003) use an alternative model for NTU-games in which the value of a coalition $S$ is defined in $\mathbb{R}^{N}$. Recently, Dietzenbacher (2018) has reanalyzed the model in Orshan et al. (2003) defining the value of coalition $S$ in $\mathbb{R}_{+}^{S}$. The following example is based on Example 7.6 in Orshan et al. (2003).

Example 1 Consider the NTU-bankruptcy problem $(N, E, c)$ with $N=\{1,2,3,4\}$, $E=\left\{x \in \mathbb{R}^{N}:\left(x_{1}+x_{3}\right)^{2}+\left(x_{2}+x_{4}\right)^{2} \leq 29\right\}$, and $c=(2,2,2,2)$. The associated game, $(N, V)$, in Orshan et al. (2003) is defined by $V(N)=\operatorname{comp}(E)$ and

$$
V(S)= \begin{cases}\operatorname{comp}\left(\left\{x \in \mathbb{R}_{+}^{N}: x_{S}=0\right\}\right) & \text { if }\left(0_{S}, c_{N \backslash S}\right) \notin E, \\ \operatorname{comp}\left(\left\{x \in \mathbb{R}_{+}^{N}:\left(x_{S}, c_{N \backslash S}\right) \in E\right\}\right) & \text { if }\left(0_{S}, c_{N \backslash S}\right) \in E\end{cases}
$$

for all $S \subset N, S \neq N$. Then, $x=(3,0,3,0) \in V(\{1,2\})$ since $\left(x_{1}+c_{3}\right)^{2}+\left(x_{2}+\right.$ $\left.c_{4}\right)^{2}=25+4=29$. Similarly, $x=(3,0,3,0) \in V(\{3,4\})$. However, $c_{1}<x_{1}=3$ and $c_{3}<x_{3}=3$. In our opinion, this is in conflict with the ideas underlying the definition of bankruptcy games in the transferable utility setting.

Next, we propose an alternative way to define NTU-bankruptcy games.

Definition 1 Let $(N, E, c)$ be an NTU-bankruptcy problem. Then, the associated NTU-bankruptcy game, $\left(N, V_{E, c}\right)$, is defined by $V_{E, c}(\emptyset)=\emptyset, V_{E, c}(N)=\operatorname{comp}(E)$, and $^{4}$

$$
V_{E, c}(S)= \begin{cases}\operatorname{comp}\left(\left\{0_{S}\right\}\right) & \text { if }\left(0_{S}, c_{N \backslash S}\right) \notin E, \\ \operatorname{comp}\left(\left\{x \in \mathbb{R}^{S}: x \leq c_{S},\left(x, c_{N \backslash S}\right) \in E\right\}\right) & \text { if }\left(0_{S}, c_{N \backslash S}\right) \in E,\end{cases}
$$

\footnotetext{
3 The non-levelness condition is a weaker version of the non-levelness property in Aumann (1985) where the restriction $y_{i} \geq v(i)$ for every $i \in N$ is not required.

4 To strictly respect the bankruptcy setting, one should perhaps define the value of the grand coalition as comp $(\{x \in \mathrm{WP}(E): x \leq c\})$. This, however, does not modify our results.
} 
for every $S \in 2^{N} \backslash\{\emptyset, N\}$.

Clearly, for every $i \in N$,

$$
v_{E, c}(i)= \begin{cases}0 & \text { if }\left(0_{\{i\}}, c_{N \backslash\{i\}}\right) \notin E, \\ \max \left\{t \in \mathbb{R}:\left(t, c_{N \backslash\{i\}}\right) \in E\right\} & \text { if }\left(0_{\{i\}}, c_{N \backslash\{i\}}\right) \in E\end{cases}
$$

and $c_{i} \geq v_{E, c}(i) \geq 0$. Moreover, NTU-bankruptcy games as defined above indeed satisfy the conditions of NTU-games. In fact, given $S \in 2^{N} \backslash\{\emptyset\}, V(S)$ is obviously nonempty, closed (because $E$ is closed according to condition (E1) of NTU-bankruptcy problems), and comprehensive by definition. Moreover, $V_{E, c}(S) \cap\left(\{x\}+\mathbb{R}_{+}^{S}\right)$ is bounded for every $x \in \mathbb{R}^{S}$ by condition (E2) of NTU-bankruptcy problems. Further, NTU-bankruptcy games are $N$-convex by (E1) and non-leveled by (E4). We deviate from the definition in Orshan et al. (2003) and Dietzenbacher (2018), not only in the NTU-modeling, but also in the way to define the value of a coalition $S$. Respecting the rules of the underlying bankruptcy setting, our definition guarantees that no claimant gets neither more than his claim, nor less than zero.

Example 2 Reconsider the NTU-bankruptcy problem $(N, E, c)$ of Example 1. Now, $(3,0) \notin V_{E, c}(\{1,2\})$.

The maximum value that individual players can achieve is $v_{E, c}(i)=\sqrt{13}-2$ for each $i \in N$. The sets $V_{E, c}(\{1,2\}), V_{E, c}(\{1,3\})$, and $V_{E, c}(\{1,2,3\})$, as provided by Definition 1, are given in Fig. 1.

\section{Convexity and core cover for NTU-games}

Convexity and compromise stability are two important concepts for TU-games. Convex games were first introduced in Shapley (1971) and correspond to those games for which the core and the convex hull of all marginal vectors of the game coincide (see Weber 1988). Compromise-stable games were first introduced in Quant et al. (2005) as those with nonempty core for which the core and core cover (cf. Tijs and Lipperts 1982) coincide. Quant et al. (2005) show that bankruptcy games are convex and compromise stable and that any TU-game that is convex and compromise stable is $S$-equivalent ${ }^{5}$ to a bankruptcy game.

We will prove in Sect. 5 that NTU-bankruptcy games inherit analogues of the properties of convexity and compromise stability. To this end, this section focuses on the main notions of convexity for NTU-games as discussed in the literature and on introducing an analogue of compromise stability for NTU-games.

An NTU-game $(N, V)$ is superadditive (Hendrickx et al. 2002) if for all $S, T \in$ $2^{N} \backslash\{\emptyset\}, S \cap T=\emptyset, V(S) \times V(T) \subset V(S \cup T)$.

The set of individually rational allocations for $S, \operatorname{IR}(S)$, is defined by

$$
\operatorname{IR}(S)=\left\{x \in V(S): x_{i} \geq v(i) \text { for every } i \in S\right\} .
$$

\footnotetext{
5 Two TU-games $(N, v)$ and $(N, w)$ are $S$-equivalent if there exist $a \in \mathbb{R}^{N}$ and $k>0$ such that $w(S)=$ $k v(S)+\sum_{i \in S} a_{i}$ for every $S \in 2^{N} \backslash\{\emptyset\}$.
} 

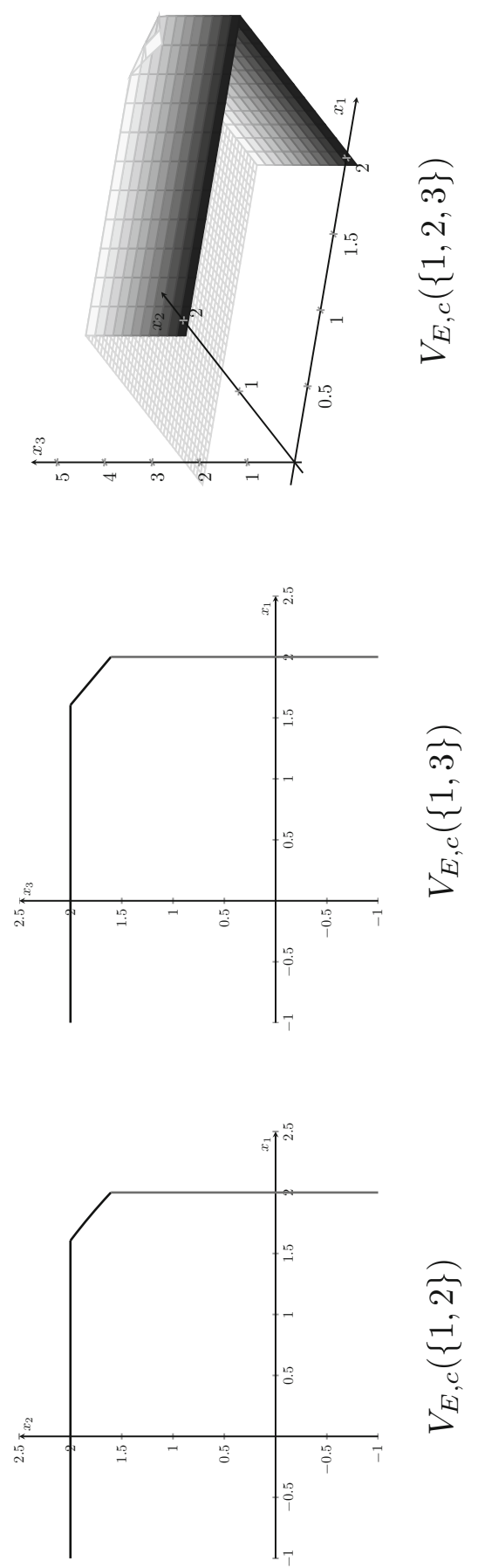

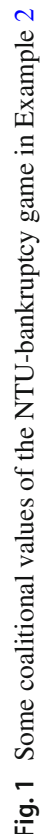


There are several convexity notions for NTU-games in the literature. An NTUgame $(N, V)$ is ordinally convex (Vilkov 1977) if it is superadditive and for all $S, T \in$ $2^{N} \backslash\{\emptyset\}$ with $S \cap T \neq \emptyset$, and all $x \in \mathbb{R}^{N}$ with $x_{S} \in V(S)$ and $x_{T} \in V(T)$,

$$
x_{S \cap T} \in V(S \cap T) \text {, or } x_{S \cup T} \in V(S \cup T) \text {; }
$$

$(N, V)$ is cardinally convex (Sharkey 1981) if for all $S, T \in 2^{N} \backslash\{\emptyset\}$,

$$
V^{0}(S)+V^{0}(T) \subset V^{0}(S \cap T)+V^{0}(S \cup T),
$$

where $V^{0}(R)=V(R) \times\left\{0_{N \backslash R}\right\}$ for all $R \in 2^{N} \backslash\{\emptyset\}$, and $V^{0}(\emptyset)=\left\{0_{N}\right\}$; and, finally, $(N, V)$ is coalition-merge convex (Hendrickx et al. 2002) if it is superadditive and for all $R \in 2^{N} \backslash\{\emptyset\}$ and all $S, T \in 2^{N}, S \subset T \subset N \backslash R$, with $S \neq T$, the following statement is true:

for all $x \in \mathrm{WP}(V(S)) \cap \operatorname{IR}(S)$, all $y \in V(T)$, and all $z \in V(S \cup R)$ such that $z_{S} \geq x$, there exists an $a \in V(T \cup R)$ such that $a_{T} \geq y$ and $a_{R} \geq z_{R}$.

It turns out that ordinal convexity and coalition-merge convexity are strong, but independent, properties. For this and for a summary of convexity notions in the literature and their relations, we refer to Hendrickx et al. (2002).

Borm et al. (1992) generalize the concepts of utopia payoff and minimal right of a player for TU-games (see Tijs 1981; Tijs and Lipperts 1982) to NTU-games. Let $(N, V)$ be an NTU-game and let $i \in N$. The utopia payoff to player $i, K_{i}(V)$, is defined by

$$
K_{i}(V)=\sup \left\{\begin{array}{ll}
t \in \mathbb{R}: & \text { there exists } a \in \mathbb{R}^{N \backslash\{i\}} \text { with }(a, t) \in V(N), \\
& a \geq(v(j))_{j \in N \backslash\{i\}}
\end{array}\right\}
$$

$K_{i}(V)<\infty$ for every $i \in N$ by condition (3) of an NTU-game.

In order to define the minimal right of player $i$, we first introduce some extra notation. We denote $\rho_{i}^{\{i\}}(V)=v(i)$ and for every $S \in 2^{N} \backslash\{\{i\}\}$ with $S \ni i, \rho_{i}^{S}(V)$ is the highest amount that player $i$ can obtain if coalition $S$ forms by giving the players in $S \backslash\{i\}$ (slightly) more than their utopia payoffs. Formally,

$$
\begin{aligned}
\rho_{i}^{S}(V)= & \sup \left\{t \in \mathbb{R}: \text { there exists } a \in \mathbb{R}^{S \backslash\{i\}} \text { with }(a, t) \in V(S)\right. \text { and } \\
& \left.a>K_{S \backslash\{i\}}(V)\right\} .
\end{aligned}
$$

The value $\rho_{i}^{S}(V)$ might equal $-\infty$. The minimal right of player $i \in N, k_{i}(V)$, is defined by

$$
k_{i}(V)=\max _{S \in 2^{N}: S \ni i}\left\{\rho_{i}^{S}(V)\right\} .
$$


The core of an NTU-game $(N, V)$, Core $(V)$, is defined by

$$
\operatorname{Core}(V)=\left\{x \in V(N) \text { : there is no } S \in 2^{N} \backslash\{\emptyset\} \text { with } x_{S} \in \operatorname{Dom}(V(S))\right\} \text {. }
$$

By definition, Core $(V) \subset \mathrm{WP}(V(N))$. Moreover, ordinally convex games have a nonempty core (Greenberg 1985).

Theorem 1 (Borm et al. 1992) Let $(N, V)$ be an NTU-game with $x \in \operatorname{Core}(V)$. Then,

$$
k(V) \leq x \leq K(V) .
$$

Tijs and Lipperts (1982) introduce the core cover for TU-games as the set of efficient allocations that are bounded from below by the vector of minimal rights and from above by the vector of utopia payoffs. Here, we generalize this concept to NTU-games. The core cover of an NTU-game $(N, V), \mathrm{CC}(V)$, is defined by

$$
\mathrm{CC}(V)=\{x \in \mathrm{WP}(V(N)): k(V) \leq x \leq K(V)\} .
$$

By Theorem 1, it follows that the core of an NTU-game is contained in its core cover.

We say that an NTU-game $(N, V)$ is compromise admissible if it has a nonempty core cover. Clearly, if the core of the game is nonempty, then, the game is NTUcompromise admissible.

Following the concept of compromise-stable TU-game (Quant et al. 2005), we say that an NTU-game $(N, V)$ is compromise stable if it is compromise admissible and $\mathrm{CC}(V)=\operatorname{Core}(V)$.

Borm et al. (1992) define the compromise value of compromise-admissible NTU games. Let $(N, V)$ be an NTU-compromise-admissible game. The compromise value, $T(V)$, is defined as the unique vector on the line segment between $k(V)$ and $K(V)$ which lies in $V(N)$ and is closest to the utopia vector $K(V)$. Formally,

$$
T(V)=\lambda K(V)+(1-\lambda) k(V),
$$

where $\lambda=\max \{\tilde{\lambda} \in[0,1]: \tilde{\lambda} K(V)+(1-\tilde{\lambda}) k(V) \in V(N)\} \cdot \lambda$ is well-defined because $^{6} k(V) \in V(N)$ and $V(N)$ is closed and comprehensive.

As an illustration of a compromise-stable game, consider the following example.

Example 3 Let $N=\{1,2,3\}$. The NTU-game $(N, V)$ is defined by

$$
\begin{aligned}
V(\{i\}) & =\left\{x_{i} \in \mathbb{R}: x_{i} \leq 0\right\}, \\
V(\{1,2\}) & =\operatorname{comp}\left(\left\{x \in \mathbb{R}^{\{1,2\}}: 4 x_{1}^{2}+4 x_{2}^{2}=1\right\}\right), \\
V(\{1,3\}) & =\operatorname{comp}\left(\left\{x \in \mathbb{R}^{\{1,3\}}: x_{1}=\frac{1}{4}, x_{3}=\frac{1}{2}\right\}\right),
\end{aligned}
$$

\footnotetext{
$\overline{6}$ For a compromise-admissible game, compromise admissibility implies $k(V) \in V(N)$.
} 


$$
\begin{array}{r}
V(\{2,3\})=\operatorname{comp}\left(\left\{x \in \mathbb{R}^{\{2,3\}}: x_{2}=\frac{1}{4}, x_{3}=\frac{1}{2}\right\}\right), \\
V(N)=\operatorname{comp}\left(\left\{x \in \mathbb{R}_{+}^{N}: 4 x_{1}^{2}+4 x_{2}^{2}+x_{3}^{2}=1\right\}\right) .
\end{array}
$$

Then,

$$
\begin{aligned}
\operatorname{Core}(V) & =\left\{x \in \mathbb{R}_{+}^{N}: x_{1} \geq \frac{1}{4}, x_{2} \geq \frac{1}{4}, x_{3}=0,4 x_{1}^{2}+4 x_{2}^{2}=1\right\}, \\
K(V) & =\left(\frac{\sqrt{3}}{4}, \frac{\sqrt{3}}{4}, 0\right), k(V)=\left(\frac{1}{4}, \frac{1}{4}, 0\right), T(V)=\left(\frac{1}{2 \sqrt{2}}, \frac{1}{2 \sqrt{2}}, 0\right)
\end{aligned}
$$

and

$$
\begin{aligned}
\mathrm{CC}(V)= & \left\{x \in \operatorname{WP}(V(N)):\left(\frac{1}{4}, \frac{1}{4}, 0\right) \leq x \leq\left(\frac{\sqrt{3}}{4}, \frac{\sqrt{3}}{4}, 0\right)\right. \text { and } \\
& \left.4 x_{1}^{2}+4 x_{2}^{2}+x_{3}^{2}=1\right\}=\operatorname{Core}(V) .
\end{aligned}
$$

Therefore, $(N, V)$ is compromise stable.

Quant et al. (2005) characterize a compromise-stable TU-game as a compromiseadmissible game for which the coalitional values never exceed the maximum of two values: the sum of the minimal rights of the members of the coalition, and what is left of the value of the grand coalition after given the outside players their utopia values. We partially generalize this result to NTU-games in Theorem 2 for non-leveled NTUgames.

Theorem 2 Let $(N, V)$ be a non-leveled compromise-admissible NTU-game. If for every $S \in 2^{N} \backslash\{\emptyset\}$, at least one of the following two conditions is satisfied,

(i) $V(S) \subset\left\{x \in \mathbb{R}^{S}: x \leq k_{S}(V)\right\}$, or

$$
\begin{gathered}
V(S) \subset \operatorname{comp}\left(\left\{x \in \mathbb{R}^{S}: \text { there exists } y \in W P(V(N)) \text { with } y_{S}=x\right.\right. \\
\text { and } \left.\left.y_{N \backslash S} \geq K_{N \backslash S}(V)\right\}\right),
\end{gathered}
$$

then, $(N, V)$ is compromise stable.

Proof We show that $(N, V)$ is compromise stable, that is, Core $(V)=\mathrm{CC}(V)$. By Theorem 1, we know that $\operatorname{Core}(V) \subset \mathrm{CC}(V)$; therefore, we only have to show that Core $(V) \supset \mathrm{CC}(V)$.

Let $z \in \mathrm{CC}(V)$. Then,

$$
z \in \mathrm{WP}(V(N)) \text { and } k(V) \leq z \leq K(V)
$$


Moreover, since $k_{i}(V) \geq v(i)$ for all $i \in N$, we have that

$$
z_{S} \in \operatorname{IR}(S) \text { for every } S \in 2^{N} \backslash\{\emptyset\} .
$$

We prove that $z \in \operatorname{Core}(V)$, that is, for every $S \in 2^{N} \backslash\{\emptyset\}, z_{S} \notin \operatorname{Dom}(V(S))$. Let $S \in 2^{N} \backslash\{\emptyset\}$.

First, assume $V(S) \subset\left\{x \in \mathbb{R}^{S}: x \leq k_{S}(V)\right\}$. Then, $z_{S} \geq k_{S}(V) \geq y$ for every $y \in V(S)$. Therefore, $z_{S} \notin \operatorname{Dom}(V(S))$.

Second, assume $V(S) \subset \operatorname{comp}\left(\left\{x \in \mathbb{R}^{S}:\right.\right.$ there exists $y \in \mathrm{WP}(V(N))$ with $y_{S}=x$ and $\left.\left.y_{N \backslash S} \geq K_{N \backslash S}(V)\right\}\right)$. We proceed by contradiction. Suppose that $z_{S} \in$ $\operatorname{Dom}(V(S))$. Then, there exists $y \in \operatorname{WP}(V(S))$ with $y>z_{S}$ and, by assumption, there exists $\tilde{y} \in \operatorname{WP}(V(N))$ such that $\tilde{y}_{S} \geq y>z_{S}$ and $\tilde{y}_{N \backslash S} \geq K_{N \backslash S}(V)$. Then, $\left(z_{S}, K_{N \backslash S}(V)\right) \in \operatorname{IR}(N) \cap \mathrm{WP}(V(N))$ and the non-levelness condition imply $\tilde{y}=$ $\left(z_{S}, K_{N \backslash S}(V)\right)$. This establishes a contradiction to our premise $\tilde{y}_{S}>z_{S}$.

The following example, however, illustrates that the sufficient conditions in Theorem 2 are not necessary ones to achieve compromise stability.

Example 4 Reconsider the compromise-stable NTU-game of Example 3. For $S=$ $\{1,3\}$, however, conditions (i) and (ii) in Theorem 2 are not satisfied: $\left(\frac{1}{4}, \frac{1}{2}\right) \in$ $V(\{1,3\})$ and

$$
\left(\frac{1}{4}, \frac{1}{2}\right) \notin\left\{x \in \mathbb{R}^{\{1,3\}}: x_{\{1,3\}} \leq k_{\{1,3\}}(V)\right\}=\left\{x \in \mathbb{R}^{\{1,3\}}: x_{1} \leq \frac{1}{4}, x_{3} \leq 0\right\}
$$

and

$$
\begin{aligned}
& \left(\frac{1}{4}, \frac{1}{2}\right) \notin \operatorname{comp}\left(\left\{x \in \mathbb{R}^{\{1,3\}}: \text { there exists } y \in \operatorname{WP}(V(N)) \text { with } y_{\{1,3\}}=x_{\{1,3\}}\right.\right. \\
& \left.\left.\quad \text { and } y_{2} \geq K_{2}(V)=\frac{\sqrt{3}}{4}\right\}\right) \\
& =\operatorname{comp}\left(\left\{x \in \mathbb{R}_{+}^{\{1,3\}}: \text { there exists } y_{2} \in \mathbb{R} \text { with } 4 x_{1}^{2}+4 y_{2}^{2}+x_{3}^{2}=1\right.\right. \\
& \left.\left.\quad \text { and } y_{2} \geq \frac{\sqrt{3}}{4}\right\}\right) .
\end{aligned}
$$

The non-levelness requirement is key in the proof of Theorem 2. In fact, Theorem 2 need not hold in games not satisfying the non-levelness condition, as the following example illustrates. 
Example 5 Consider the 4-player NTU-game $(N, V)$ defined by

$$
\begin{array}{ll}
V(\{i\})=\left\{x_{i} \in \mathbb{R}: x_{i} \leq 0\right\} & \text { for every } i \in N, \\
V(S)=\left\{x \in \mathbb{R}^{S}: x_{i} \leq 2 \text { for every } i \in S\right\} & \text { for every } S \in 2^{N},|S|=2, \\
V(S)=\left\{x \in \mathbb{R}^{S}: x_{i} \leq 4 \text { for every } i \in S\right\} & \text { for every } S \in 2^{N},|S|=3, \\
V(N)=\left\{x \in \mathbb{R}^{N}: x_{i} \leq 7 \text { for every } i \in N\right\} &
\end{array}
$$

This NTU-game is not non-leveled. Here, $K(V)=(7,7,7,7)$ and $k(V)=(0,0,0,0)$. Therefore, the game satisfies the conditions in Theorem 2 since

$$
\begin{aligned}
& V(S) \subset \operatorname{comp}\left(\left\{x \in \mathbb{R}^{S}: \text { there exists } y \in \mathrm{WP}(V(N)) \text { with } y_{S}=x_{S}\right.\right. \\
& \text { and } \left.\left.y_{N \backslash S} \geq K_{N \backslash S}(V)\right\}\right) .
\end{aligned}
$$

However, $\operatorname{Core}(V) \neq \mathrm{CC}(V)$. To see this, notice that

$$
\mathrm{CC}(V)=\left\{x \in \mathbb{R}^{N}: 0 \leq x_{i} \leq 7 \text { for every } i \in N \text { and } x_{j}=7 \text { for some } j \in N\right\},
$$

$(1,1,7,7) \in \mathrm{CC}(V)$, and $(1,1) \in \operatorname{Dom}(V(\{1,2\}))$, which implies $(1,1,7,7) \notin$ Core $(V)$.

Next, we generalize some results of Curiel et al. (1987) on truncated claims, utopia vectors, and minimal rights to the NTU-setting.

Let $(N, E, c)$ be an NTU-bankruptcy problem. We denote by $c^{t} \in \mathbb{R}^{N}$ the truncated vector of claims defined, for every $i \in N$, by

$$
c_{i}^{t}= \begin{cases}c_{i} & \text { if }\left(c_{i}, 0_{N \backslash\{i\}}\right) \in E, \\ \max \left\{\tilde{t} \in \mathbb{R}:\left(\tilde{t}, 0_{N \backslash\{i\}}\right) \in E\right\} & \text { if }\left(c_{i}, 0_{N \backslash\{i\}}\right) \notin E .\end{cases}
$$

Notice that $c^{t} \in \mathbb{R}_{+}^{N}$ and $\left(c_{i}^{t}, 0_{N \backslash\{i\}}\right) \in \mathrm{WP}(E)$ for every $i \in N$ with $c_{i}^{t}<c_{i}$. Next, we show that the properties related to claims truncation shown in Curiel et al. (1987) for TU-bankruptcy games are also satisfied for NTU-bankruptcy games. The proof of this proposition uses the following lemma.

Lemma 1 Let $(N, E, c)$ be an NTU-bankruptcy problem, let $i \in N$, and let $x, y \in \mathbb{R}^{N \backslash\{i\}}$ with $x \leq y, x \neq y$, and $(x, 0),(y, 0) \in E$. Then, with $t_{x}=$ $\max \{t \in \mathbb{R} \mid(x, t) \in E\}$ and $t_{y}=\max \{t \in \mathbb{R} \mid(y, t) \in E\}$,

$$
t_{x}>t_{y} .
$$

Proof On the contrary, suppose that $t_{x} \leq t_{y}$. We have $x, y \in \mathbb{R}_{+}^{N \backslash\{i\}}$ since $(x, 0),(y, 0) \in E$ and $E \subset \mathbb{R}_{+}^{N}$. Since $E$ is closed and bounded, we have that $E$ is compact, $t_{x}, t_{y} \in \mathbb{R}_{+}$, and

$$
\left(x, t_{x}\right),\left(y, t_{y}\right) \in \mathrm{WP}(E) .
$$


Since $x \leq y, t_{x} \leq t_{y}$, and $\left(x, t_{x}\right),\left(y, t_{y}\right) \in \mathrm{WP}(E)$, we have $\left(x, t_{x}\right)=\left(y, t_{y}\right)$ by condition (E4). This establishes a contradiction to our premise $x \neq y$.

Proposition 1 Let $(N, E, c)$ be an NTU-bankruptcy problem and let $\left(N, V_{E, c}\right)$ be the associated NTU-bankruptcy game. Then,

(i) $V_{E, c}=V_{E, c^{t}}$,

(ii) $K\left(V_{E, c}\right)=c^{t}$, and

(iii) $k\left(V_{E, c}\right)=\left(v_{E, c}(i)\right)_{i \in N}$.

Proof (i) $V_{E, c}=V_{E, c^{t}}$.

First, $V_{E, c}(\emptyset)=\emptyset=V_{E, c^{t}}(\emptyset)$ and $V_{E, c}(N)=\operatorname{comp}(E)=V_{E, c^{t}}(N)$ by definition of NTU-bankruptcy games. Second, let $S \in 2^{N} \backslash\{\emptyset, N\}$. We distinguish between two cases: (1) $\left(0_{S}, c_{N \backslash S}\right) \in E$ and (2) $\left(0_{S}, c_{N \backslash S}\right) \notin E$.

Case 1: $\left(0_{S}, c_{N \backslash S}\right) \in E$.

By condition (E3) of NTU-bankruptcy problems and by definition of $c^{t}, c_{N \backslash S}^{t}=$ $c_{N \backslash S}$ and $\left(0_{S}, c_{N \backslash S}^{t}\right) \in E$. If $c_{S}^{t}=c_{S}$, then,

$$
\begin{aligned}
V_{E, c^{t}}(S) & =\operatorname{comp}\left(\left\{x \in \mathbb{R}^{S}: x \leq c_{S}^{t},\left(x, c_{N \backslash S}^{t}\right) \in E\right\}\right) \\
& =\operatorname{comp}\left(\left\{x \in \mathbb{R}^{S}: x \leq c_{S},\left(x, c_{N \backslash S}\right) \in E\right\}\right)=V_{E, c}(S) .
\end{aligned}
$$

If $c_{S}^{t} \neq c_{S}$, then, $c_{N \backslash S}^{t}=c_{N \backslash S}$ and $c_{S}^{t} \leq c_{S}$ imply that

$$
\begin{aligned}
V_{E, c^{t}}(S) & =\operatorname{comp}\left(\left\{x \in \mathbb{R}^{S}: x \leq c_{S}^{t},\left(x, c_{N \backslash S}^{t}\right) \in E\right\}\right) \\
& \subset \operatorname{comp}\left(\left\{x \in \mathbb{R}^{S}: x \leq c_{S},\left(x, c_{N \backslash S}\right) \in E\right\}\right)=V_{E, c}(S) .
\end{aligned}
$$

To show the other inclusion, we proceed by contradiction. Suppose that $x \in$ $V_{E, c}(S)$ and $x \notin V_{E, c^{t}}(S)$. Then, there exists $i \in S$ such that $x_{i}>c_{i}^{t}$. Since $x \in V_{E, c}(S)$, we have $c_{i}^{t}<x_{i} \leq c_{i}$. Moreover, if $x_{j}<0$ for some $j \in S$, we have that $x^{+} \in \mathbb{R}_{+}^{S}$ defined by $x_{j}^{+}=\max \left\{x_{j}, 0\right\}$ for every $j \in S$ belongs to $E$ by definition of $V_{E, c}(S)$. By condition (E3) of NTU-bankruptcy problems, we have that $\left(x_{i}, 0_{N \backslash\{i\}}\right) \in E$ with $x_{i}>c_{i}^{t}$. This establishes a contradiction with the definition of $c_{i}^{t}$.

Case 2: $\left(0_{S}, c_{N \backslash S}\right) \notin E$.

In this case, we distinguish between two situations: (2.a) $\left(0_{S}, c_{N \backslash S}^{t}\right) \notin E$ and (2.b) $\left(0_{S}, c_{N \backslash S}^{t}\right) \in E$.

Case 2.a: $\left(0_{S}, c_{N \backslash S}^{t}\right) \notin E$.

Then,

$$
V_{E, c^{t}}(S)=\operatorname{comp}\left(\left\{0_{S}\right\}\right)=V_{E, c}(S) .
$$

Case 2.b: $\left(0_{S}, c_{N \backslash S}^{t}\right) \in E$.

In this case, $c_{N \backslash S}^{t} \neq c_{N \backslash S}$. Moreover, there is $i \in N \backslash S$ such that either $N \backslash S=\{i\}$, or $c_{j}^{t}=0$ for every $j \in N \backslash S, j \neq i$. 
We show this claim by contradiction. Assume that $|N \backslash S|>1$ and that there are $i, j \in N \backslash S, i \neq j$, with $c_{i}^{t}, c_{j}^{t}>0$. By our assumption and condition (E3), we have that $\left(0_{N \backslash\{i, j\}}, c_{j}^{t}, c_{i}^{t}\right) \in E$. If $\left(0_{N \backslash\{i, j\}}, c_{j}^{t}, c_{i}^{t}\right) \in \mathrm{WP}(E)$, then, $\left(0_{N \backslash\{i\}}, c_{i}^{t}\right) \in \mathrm{WP}(E)$ and (E4) imply $\left(0_{N \backslash\{i, j\}}, c_{j}^{t}, c_{i}^{t}\right)=\left(0_{N \backslash\{j\}}, c_{i}^{t}\right)$. This establishes a contradiction to our premise $c_{j}^{t}>0$.

If $\left(0_{N \backslash\{i, j\}}, c_{j}^{t}, c_{i}^{t}\right) \in E \backslash \mathrm{WP}(E)$, then, by Lemma 1 , $\max \left\{t \in \mathbb{R} \mid\left(0_{N \backslash\{i, j\}}, c_{j}^{t}, t\right) \in E\right\}<\max \left\{t \in \mathbb{R} \mid\left(0_{N \backslash\{i\}}, t\right) \in E\right\}=c_{i}^{t}$. This establishes a contradiction to our premise $\left(0_{N \backslash\{i, j\}}, c_{j}^{t}, c_{i}^{t}\right) \in E$.

Then, $\left(0_{S}, c_{N \backslash S}^{t}\right) \in \mathrm{WP}(E)$ and

$$
V_{E, c^{t}}(S)=\operatorname{comp}\left(\left\{0_{S}\right\}\right)=V_{E, c}(S) .
$$

(ii) $K\left(V_{E, c}\right)=c^{t}$.

Since $V_{E, c}=V_{E, c^{t}}$, it suffices to show that $K\left(V_{E, c^{t}}\right)=c^{t}$. Let $i \in N$. If $\left(0_{N \backslash\{i\}}, c_{i}\right) \in E$, then, $c_{i}^{t}=c_{i}$. If $\left(0_{N \backslash\{i\}}, c_{i}\right) \notin E$, then, $c_{i}^{t}<c_{i}$ and $\left(0_{N \backslash\{i\}}, c_{i}^{t}\right) \in$ $\mathrm{WP}(E)$. Then,

$$
V_{E, c^{t}}(N \backslash\{i\})=\operatorname{comp}\left(\left\{x \in \mathbb{R}^{N \backslash\{i\}}: x \leq c_{N \backslash\{i\}}^{t},\left(x, c_{i}^{t}\right) \in E\right\}\right) .
$$

First, we show that $K_{i}\left(V_{E, c^{t}}\right) \leq c_{i}^{t}$ by contradiction. Suppose that $K_{i}\left(V_{E, c^{t}}\right)>c_{i}^{t}$. From the definition of $K_{i}\left(V_{E, c^{t}}\right)$, we can choose $b \in \mathbb{R}^{N \backslash\{i\}}$ such that

(a) $\left(b, K_{i}\left(V_{E, c^{t}}\right)\right) \in \operatorname{comp}(E)$,

(b) $b \notin \operatorname{Dom}\left(V_{E, c^{t}}(N \backslash\{i\})\right)$, and

(c) $b \geq\left(v_{E, c^{t}}(j)\right)_{j \in N \backslash\{i\}}$.

Clearly, $\left(b, K_{i}\left(V_{E, c^{t}}\right)\right) \in \operatorname{WP}(E) \subset \partial E$. Moreover, $K_{i}\left(V_{E, c^{t}}\right)>c_{i}^{t}$ and $\left(b, K_{i}\left(V_{E, c^{t}}\right)\right) \in \partial E$ imply $\left(b, c_{i}^{t}\right) \in \operatorname{comp}(E)$. Since $c_{i}^{t} \geq v_{E, c^{t}}(i)$, it follows that $\left(b, c_{i}^{t}\right) \in \operatorname{IR}(N)$. Since NTU-bankruptcy games are non-leveled, $\left(b, c_{i}^{t}\right) \notin \partial E$. Therefore, there is a $y \in \partial E$ such that $y>\left(b, c_{i}^{t}\right)$. Hence, $y_{N \backslash\{i\}} \in V_{E, c^{t}}(N \backslash\{i\})$ with $y_{N \backslash\{i\}}>b$. This establishes a contradiction to our premise $b \notin \operatorname{Dom}\left(V_{E, c^{t}}(N \backslash\{i\})\right)$.

Second, we show that $K_{i}\left(V_{E, c^{t}}\right) \geq c_{i}^{t}$. For this, we show that

$$
\left(0_{N \backslash\{i\}}, c_{i}^{t}\right) \in E \text { implies that }\left(\left(v_{E, c^{t}}(j)\right)_{j \in N \backslash\{i\}}, c_{i}^{t}\right) \in E .
$$

If $\left(0_{j}, c_{N \backslash\{j\}}^{t}\right) \in E$ for some $j \in N \backslash\{i\}$, then, $\left(v_{E, c^{t}}(j), c_{N \backslash\{j\}}^{t}\right) \in E$ by definition of $v_{E, c^{t}}(j)$ which, together with $v_{E, c^{t}}(k) \leq c_{k}^{t}$ for all $k \in N \backslash\{i, j\}$, implies $\left(\left(v_{E, c^{t}}(j)\right)_{j \in N \backslash\{i\}}, c_{i}^{t}\right) \in E$ by condition (E3) of NTU-bankruptcy problems. If $\left(0_{\{j\}}, c_{N \backslash\{j\}}^{t}\right) \notin E$ for every $j \in N \backslash\{i\}$, then, $v_{E, c^{t}}(j)=0$ for every $j \in N \backslash\{i\}$ and $\left(\left(v_{E, c^{t}}(j)\right)_{j \in N \backslash\{i\}}, c_{i}^{t}\right)=\left(0_{N \backslash\{i\}}, c_{i}^{t}\right) \in E$ by definition of $c_{i}^{t}$.

Take $\tilde{t}=\max \left\{t \geq 0:\left(\left(v_{E, c^{t}}(j)+t\right)_{j \in N \backslash\{i\}}, c_{i}^{t}\right) \in E\right\}$. It follows that

(a) $\left(\left(v_{E, c^{t}}(j)+\tilde{t}\right)_{j \in N \backslash\{i\}}, c_{i}^{t}\right) \in \operatorname{comp}(E)$,

(b) $\left(v_{E, c^{t}}(j)+\tilde{t}\right)_{j \in N \backslash\{i\}} \notin \operatorname{Dom}\left(V_{E, c^{t}}(N \backslash\{i\})\right)$, and 
(c) $v_{E, c^{t}}(j)+\tilde{t} \geq v_{E, c^{t}}(j)$ for all $j \in N \backslash\{i\}$.

Therefore, $K_{i}\left(V_{E, c^{t}}\right) \geq c_{i}^{t}$.

(iii) $k\left(V_{E, c}\right)=\left(v_{E, c}(i)\right)_{i \in N}$.

Since $V_{E, c}=V_{E, c^{t}}$, it suffices to show that $k\left(V_{E, c^{t}}\right)=v_{E, c^{t}}(i)$. Let $i \in N$. By definition, $\rho_{i}^{\{i\}}\left(V_{E, c^{t}}\right)=v_{E, c^{t}}(i)$. Let $S \in 2^{N} \backslash\{\{i\}, N\}$ with $S \ni i$. Then,

$$
\begin{gathered}
\rho_{i}^{S}\left(V_{E, c^{t}}\right)=\sup \left\{t \in \mathbb{R}: \text { there exists } a \in \mathbb{R}^{S \backslash\{i\}}\right. \text { with } \\
\left.(a, t) \in V_{E, c^{t}}(S) \text { and } a>c_{S \backslash\{i\}}^{t}\right\} .
\end{gathered}
$$

If $\left(0_{S}, c_{N \backslash S}^{t}\right) \notin E$, then, $\rho_{i}^{S}\left(V_{E, c^{t}}\right)=-\infty$ because for any $t \in \mathbb{R}$, we cannot find $a \in \mathbb{R}^{S \backslash\{i\}}$ with $(a, t) \in V_{E, c^{t}}(S)$ and $a>c_{S \backslash\{i\}}^{t}$ since $(a, t) \in V_{E, c^{t}}(S)$ implies $a \leq 0_{S \backslash\{i\}} \leq c_{S \backslash\{i\}}^{t}$.

If $\left(0_{S}, c_{N \backslash S}^{t}\right) \in E$, then, $\rho_{i}^{S}\left(V_{E, c^{t}}\right)=-\infty$ because for any $t \in \mathbb{R}$, we cannot find $a \in \mathbb{R}^{S \backslash\{i\}}$ with $(a, t) \in V_{E, c^{t}}(S)$ and $a>c_{S \backslash\{i\}}^{t}$ since $(a, t) \in V_{E, c^{t}}(S)$ implies $a \leq c_{S \backslash\{i\}}^{t}$.

Last, we analyze $\rho_{i}^{N}\left(V_{E, c^{t}}\right)$. Notice that $\rho_{i}^{N}\left(V_{E, c^{t}}\right)$ is given by

$$
\begin{gathered}
\rho_{i}^{N}\left(V_{E, c^{t}}\right)=\sup \left\{t \in \mathbb{R}: \text { there exists } a \in \mathbb{R}^{N \backslash\{i\}}\right. \text { with } \\
\left.(a, t) \in \operatorname{comp}(E) \text { and } a>c_{N \backslash\{i\}}^{t}\right\} .
\end{gathered}
$$

If $\left(0_{\{i\}}, c_{N \backslash\{i\}}^{t}\right) \notin E$, then, $\rho_{i}^{N}\left(V_{E, c^{t}}\right)=-\infty$ because $\left(0_{\{i\}}, c_{N \backslash\{i\}}^{t}\right) \notin E$ and, therefore, for any $t \in \mathbb{R}$, we cannot find $a \in \mathbb{R}^{N \backslash\{i\}}$ with $(a, t) \in \operatorname{comp}(E)$ and $a>c_{N \backslash\{i\}}^{t}$.

If $\left(0_{\{i\}}, c_{N \backslash\{i\}}^{t}\right) \in E$, then,

$$
\rho_{i}^{N}\left(V_{E, c^{t}}\right)= \begin{cases}-\infty & \text { if }\left(0_{\{i\}}, c_{N \backslash\{i\}}^{t}\right) \in \partial E, \\ v_{E, c^{t}}(i) & \text { if }\left(0_{\{i\}}, c_{N \backslash\{i\}}^{t}\right) \notin \partial E .\end{cases}
$$

Therefore, it follows that $k_{i}\left(V_{E, c^{t}}\right)=v_{E, c^{t}}(i)$.

Next, we generalize a result in Estévez-Fernández et al. (2012) stating that the core cover of a compromise-admissible TU-game can be obtained as a translation of the core cover of a TU-bankruptcy game to the NTU-setting.

Theorem 3 Let $(N, V)$ be an $N$-convex, ${ }^{7}$ non-leveled, compromise-admissible NTUgame with $V(N) \cap \mathbb{R}_{++}^{N} \neq \emptyset$. Then, $C C(V)=\{k(V)\}+C C\left(V_{E, c}\right)$, where $E=$ $(V(N)-\{k(V)\}) \cap \mathbb{R}_{++}^{N}$ and $c=K(V)-k(V)$.

\footnotetext{
7 Theorem 3 also holds for non-leveled NTU-games that are not $N$-convex.
} 
Proof First, we show that $(N, E, c)$, with $E=(V(N)-\{k(V)\}) \cap \mathbb{R}_{++}^{N}$ and $c=$ $K(V)-k(V)$, is an NTU-bankruptcy problem. $E=V(N)-\{k(V)\}$ can be interpreted as a translation of the center of coordinates to $k(V)$. Then, (E1) follows by condition (2) of an NTU-game and because the game is $N$-convex, (E2) is a direct consequence of condition (3) of an NTU-game, (E3) follows by condition (2) of an NTU-game, ${ }^{8}$ (E4) follows since $(N, v)$ is non-leveled, (E5) follows because $\mathrm{CC}(V) \neq \emptyset$ and $K(V) \notin$ $\operatorname{int}(\operatorname{comp}(V(N)))$. Moreover, $c=K(V)-k(V)=c^{t}$ using the definition of $K(V)$.

Let $\left(N, V_{E, c}\right)$ be its corresponding NTU-bankruptcy game. By Proposition 1, we know that

$$
K\left(V_{E, c}\right)=K(V)-k(V) \quad \text { and } \quad k\left(V_{E, c}\right)=\left(v_{E, c}(i)\right)_{i \in N} .
$$

Notice that

$$
v_{E, c}(i)=0
$$

if $\left(k_{i}(V), K_{N \backslash\{i\}}(V)\right) \notin V(N)$ and

$$
v_{E, c}(i)=\sup \left\{t \in \mathbb{R}:\left(t+k_{i}(V), K_{N \backslash\{i\}}(V)\right) \in V(N)\right\}
$$

if $\left(k_{i}(V), K_{N \backslash\{i\}}(V)\right) \in V(N)$. This implies that $v_{E, c}(i)=0$ for every $i \in N$. To see this, let $\left(k_{i}(V), K_{N \backslash\{i\}}(V)\right) \in V(N)$. Clearly, since

$$
\begin{aligned}
k_{i}(V) & =\max _{S \in 2^{N}: S \ni i}\left\{\rho_{i}^{S}(V)\right\} \\
& \geq \rho_{i}^{N}(V) \\
& =\sup \left\{t \in \mathbb{R}: \text { there exists } a \in \mathbb{R}^{N \backslash\{i\}} \text { with }(a, t) \in V(N)\right. \text { and } \\
& \left.a>K_{N \backslash\{i\}}(V)\right\},
\end{aligned}
$$

it must be the case that $\left(k_{i}(V), K_{N \backslash\{i\}}(V)\right) \in \partial V(N) \cap \operatorname{IR}(N)$ which implies that $\left(k_{i}(V), K_{N \backslash\{i\}}(V)\right) \in \mathrm{WP}(V(N))$ and $v_{E, c}(i)=0$ for every $i \in N$.

Next, we show that $\mathrm{CC}(V)=\{k(V)\}+\mathrm{CC}\left(V_{E, c}\right)$. First, we prove that $\mathrm{CC}(V) \subset$ $\{k(V)\}+\mathrm{CC}\left(V_{E, c}\right)$. Let $x \in \mathrm{CC}(V)$, then, $k(V) \leq x \leq K(V)$ and $x \in \mathrm{WP}(V(N))$. Thus, $0_{N}=\left(v_{E, c}(i)\right)_{i \in N} \leq x-k(V) \leq K(V)-k(V)$ and $x-k(V) \in \mathrm{WP}\left(V_{E, c}(N)\right)$. Hence, $x-k(V) \in \mathrm{CC}\left(V_{E, c}\right)$. Last, we prove that $\mathrm{CC}(V) \supset\{k(V)\}+\operatorname{CC}\left(V_{E, c}\right)$. Let $x \in \mathrm{CC}\left(V_{E, c}\right)$. Then, $k\left(V_{E, c}\right) \leq x \leq K\left(V_{E, c}\right)$ and $x \in \mathrm{WP}\left(V_{E, c}(N)\right)$. By Proposition 1, we know that $k_{i}\left(V_{E, c}\right)=v_{E, c}(i)$ and $K_{i}\left(V_{E, c}\right)=c_{i}^{t}$ for every $i \in N$. Then, $k_{i}\left(V_{E, c}\right)=0$ and $K_{i}\left(V_{E, c}\right)=K_{i}(V)-k_{i}(V)$ for every $i \in N$. Therefore, $k(V) \leq x+k(V) \leq K(V)$ and $x+k(V) \in \mathrm{WP}(V(N))$. As a result, $x+k(V) \in$ $\mathrm{CC}(V)$.

\footnotetext{
${ }^{8}$ If $V(N) \cap \mathbb{R}_{++}^{N}=\emptyset$, we can always change the origin of coordinates such that $V(N) \cap \mathbb{R}_{++}^{N} \neq \emptyset$ and $v(i) \geq 0$ for each $i \in N$.
} 


\section{Properties of NTU-bankruptcy games}

In this section, we show that NTU-bankruptcy games are coalition-merge convex, ordinally convex, and compromise stable. However, they need not be cardinally convex.

Lemma 2 Let $(N, E, c)$ be an NTU-bankruptcy problem and let $\left(N, V_{E, c}\right)$ be the associated NTU-bankruptcy game. Let $S \in 2^{N} \backslash\{\emptyset\}$ with $\left(0_{S}, c_{N \backslash S}\right) \in E$. Then, for every $T \in 2^{N} \backslash\{\emptyset\}$ with $S \subset T$, and for every $x \in V_{E, c}(S),\left(x, c_{T \backslash S}\right) \in V_{E, c}(T)$.

Proof Since $\left(0_{S}, c_{N \backslash S}\right) \in E$, we have

$$
V_{E, c}(S)=\operatorname{comp}\left(\left\{w \in \mathbb{R}^{S}: w \leq c_{S},\left(w, c_{N \backslash S}\right) \in E\right\}\right) .
$$

Let $T \in 2^{N} \backslash\{\varnothing\}, S \subset T$. Notice that $\left(0_{S}, c_{N \backslash S}\right) \in E$ implies $\left(0_{T}, c_{N \backslash T}\right) \in E$ by condition (E3) of NTU-bankruptcy problems. Then,

$$
V_{E, c}(T)=\operatorname{comp}\left(\left\{w \in \mathbb{R}^{T}: w \leq c_{T},\left(w, c_{N \backslash T}\right) \in E\right\}\right)
$$

Let $x \in V_{E, c}(S)$. Then,

$$
\left(x, c_{T \backslash S}\right) \in \operatorname{comp}\left(\left\{w \in \mathbb{R}^{T}: w \leq c_{T},\left(w, c_{N \backslash T}\right) \in E\right\}\right)=V_{E, c}(T) .
$$

Next, we prove that all NTU-bankruptcy games are superadditive.

Lemma 3 Every NTU-bankruptcy game is superadditive.

Proof Let $(N, E, c)$ be an NTU-bankruptcy problem and let $\left(N, V_{E, c}\right)$ be the associated NTU-bankruptcy game. Let $S, T \in 2^{N} \backslash\{\emptyset\}$ with $S \cap T=\emptyset$. Let $x \in V_{E, c}(S)$ and $y \in V_{E, c}(T)$. We show that $(x, y) \in V_{E, c}(S \cup T)$. Without loss of generality, it suffices to distinguish between two cases: (1) $\left(0_{S}, c_{N \backslash S}\right) \in E$ and (2) $\left(0_{S}, c_{N \backslash S}\right) \notin E$, $\left(0_{T}, c_{N \backslash T}\right) \notin E$.

Case 1: $\left(0_{S}, c_{N \backslash S}\right) \in E$.

In this case,

$$
V_{E, c}(S)=\operatorname{comp}\left(\left\{w \in \mathbb{R}^{S}: w \leq c_{S},\left(w, c_{N \backslash S}\right) \in E\right\}\right)
$$

and there exists $\tilde{w} \in E$ with $x \leq \tilde{w}_{S} \leq c_{S}$ and $\tilde{w}_{N \backslash S}=c_{N \backslash S}$. Moreover, $\left(0_{S \cup T}, c_{N \backslash(S \cup T)}\right) \in E$ by condition (E3) of NTU-bankruptcy problems and, consequently,

$$
V_{E, c}(S \cup T)=\operatorname{comp}\left(\left\{w \in \mathbb{R}^{S \cup T}: w \leq c_{S \cup T},\left(w, c_{N \backslash(S \cup T)}\right) \in E\right\}\right)
$$


and $\tilde{w}_{S \cup T} \in V_{E, c}(S \cup T)$. Then, since $y \leq c_{T}$, we have

$$
\left(x, y, c_{N \backslash(S \cup T)}\right) \leq\left(x, c_{T}, c_{N \backslash(S \cup T)}\right) \leq \tilde{w}=\left(\tilde{w}_{S}, c_{T}, c_{N \backslash(S \cup T)}\right) \in E .
$$

Therefore, $(x, y) \in V_{E, c}(S \cup T)$.

Case 2: $\left(0_{S}, c_{N \backslash S}\right) \notin E,\left(0_{T}, c_{N \backslash T}\right) \notin E$.

Recall that $E \subset \mathbb{R}_{+}^{N}$. By definition of $\left(N, V_{E, c}\right)$, we have

$$
V_{E, c}(R)=\operatorname{comp}\left(\left\{0_{R}\right\}\right) \text { for } R \in\{S, T\} .
$$

Since $x \in V_{E, c}(S)$, we have $x \leq 0_{S}$. Similarly, $y \leq 0_{T}$.

If $\left(0_{S \cup T}, c_{N \backslash(S \cup T)}\right) \in E$, then, $\left(x, y, c_{N \backslash S \cup T}\right) \leq\left(0_{S \cup T}, c_{N \backslash(S \cup T)}\right) \in E$ and $(x, y) \in V_{E, c}(S \cup T)$.

If $\left(0_{S \cup T}, c_{N \backslash(S \cup T)}\right) \notin E$, then, $(x, y) \leq 0_{S \cup T}$ and $(x, y) \in V_{E, c}(S \cup T)$.

Theorem 4 Every NTU-bankruptcy game is coalition-merge convex.

Proof Let $(N, E, c)$ be an NTU-bankruptcy problem and let $\left(N, V_{E, c}\right)$ be the associated NTU-bankruptcy game. By Lemma 3 , we know that $\left(N, V_{E, c}\right)$ is superadditive. Let $U \subset 2^{N} \backslash\{\emptyset\}$ and $S \subset T \subset N \backslash U$ with $S \neq T$. Let $x \in \operatorname{WP}\left(V_{E, c}(S)\right) \cap \operatorname{IR}(S)$, $y \in V_{E, c}(T)$, and $z \in V_{E, c}(S \cup U)$ with $z_{S} \geq x$. We show that there exists an $a \in V_{E, c}(T \cup U)$ such that $a_{T} \geq y$ and $a_{U} \geq z_{U}$. We distinguish between two cases: (1) $\left(0_{T}, c_{N \backslash T}\right) \notin E$ and (2) $\left(0_{T}, c_{N \backslash T}\right) \in E$.

Case 1: $\left(0_{T}, c_{N \backslash T}\right) \notin E$.

First, since $V_{E, c}(T)=\operatorname{comp}\left(\left\{0_{T}\right\}\right)$,

$$
y \leq 0 \text { and, in particular, } y_{S} \leq 0 .
$$

Moreover, by condition(E3) of NTU-bankruptcy problems, we have that $\left(0_{\{i\}}, c_{N \backslash\{i\}}\right) \notin$ $E$ for every $i \in T$ and, consequently, $v_{E, c}(i)=0$ for every $i \in T$. Further, condition (E3) of NTU-bankruptcy problems and $S \subset T$ imply $\left(0_{S}, c_{N \backslash S}\right) \notin E, V_{E, c}(S)=$ comp $\left(\left\{0_{S}\right\}\right)$, and $v_{E, c}(i)=0$ for every $i \in S$. Since $x \in \operatorname{WP}\left(V_{E, c}(S)\right) \cap \operatorname{IR}(S)$, we have $x=0_{S}$. Then,

$$
z_{S} \geq x=0_{S}
$$

Consider three cases: (1.a) $\left(0_{S \cup U}, c_{N \backslash(S \cup U)}\right) \in E$, (1.b) $\left(0_{S \cup U}, c_{N \backslash(S \cup U)}\right) \notin E$, $\left(0_{T \cup U}, c_{N \backslash(T \cup U)}\right) \in E$, and (1.c) $\left(0_{S \cup U}, c_{N \backslash(S \cup U)}\right) \notin E,\left(0_{T \cup U}, c_{N \backslash(T \cup U)}\right) \notin E$.

Case 1.a: $\left(0_{S \cup U}, c_{N \backslash(S \cup U)}\right) \in E$.

Then, by condition (E3) of NTU-bankruptcy problems, $\left(0_{T \cup U}, c_{N \backslash(T \cup U)}\right) \in E$ and, consequently,

$$
V_{E, c}(R \cup U)=\operatorname{comp}\left(\left\{w \in \mathbb{R}^{R \cup U}: w \leq c_{R \cup U},\left(w, c_{N \backslash(R \cup U)}\right) \in E\right\}\right)
$$

for $R \in\{S, T\}$. Then, by Lemma $2,\left(z, c_{T \backslash S}\right) \in V_{E, c}(T \cup U)$. Choosing $a=\left(z, c_{T \backslash S}\right)$, we have $a_{U}=z_{U}$ and $a_{T} \geq y$ since $a_{S}=z_{S} \geq x=0_{S} \geq y_{S}$ and $a_{T \backslash S}=c_{T \backslash S} \geq$ $0 \geq y_{T \backslash S}$. 
Case 1.b: $\left(0_{S \cup U}, c_{N \backslash(S \cup U)}\right) \notin E,\left(0_{T \cup U}, c_{N \backslash(T \cup U)}\right) \in E$.

Then,

$$
V_{E, c}(S \cup U)=\operatorname{comp}\left(\left\{0_{S \cup U}\right\}\right)
$$

and

$$
V_{E, c}(T \cup U)=\operatorname{comp}\left(\left\{w \in \mathbb{R}^{T \cup U}: w \leq c_{T \cup U},\left(w, c_{N \backslash(T \cup U)}\right) \in E\right\}\right) .
$$

Choose $a=0_{T \cup U} \in V_{E, c}(T \cup U)$. Since $z \in V_{E, c}(S \cup U), z_{U} \leq 0_{U}$. Then, $a_{U}=0_{U} \geq z_{U}$ and $a_{T}=0_{T} \geq y_{T}$.

Case 1.c: $\left(0_{S \cup U}, c_{N \backslash(S \cup U)}\right) \notin E,\left(0_{T \cup U}, c_{N \backslash(T \cup U)}\right) \notin E$.

Then,

$$
V_{E, c}(R \cup U)=\operatorname{comp}\left(\left\{0_{R \cup U}\right\}\right)
$$

for $R \in\{S, T\}$. Choose $a=0_{T \cup U} \in V_{E, c}(T \cup U)$. Since $z \in V_{E, c}(S \cup U), z_{U} \leq 0_{U}$. Then, $a_{U}=0_{U} \geq z_{U}$ and $a_{T}=0_{T} \geq y_{T}$.

Case 2: $\left(0_{T}, c_{N \backslash T}\right) \in E$.

By condition (E3) of NTU-bankruptcy problems, $\left(0_{T \cup U}, c_{N \backslash(T \cup U)}\right) \in E$ and, then,

$$
V_{E, c}(R)=\operatorname{comp}\left(\left\{w \in \mathbb{R}^{R}: w \leq c_{R},\left(w, c_{N \backslash R}\right) \in E\right\}\right)
$$

for $R \in\{T, T \cup U\}$. Since $y \in V_{E, c}(T),\left(y, c_{U}\right) \in V_{E, c}(T \cup U)$ by Lemma 2 . Choosing $a=\left(y, c_{U}\right)$, we have $a_{T}=y$ and $a_{U}=c_{U} \geq z_{U}$ where the last inequality follows from $z \in V_{E, c}(S \cup U)$.

Hendrickx et al. (2002) show that every coalition-merge convex game is marginal convex. This means that for bankruptcy games, every marginal vector belongs to the core. As a consequence, bankruptcy games are also reasonable stable (cf. Dietzenbacher 2018).

Theorem 5 Every NTU-bankruptcy game is ordinally convex.

Proof Let $(N, E, c)$ be an NTU-bankruptcy problem and let $\left(N, V_{E, c}\right)$ be the associated NTU-bankruptcy game. By Lemma 3 , we know that $\left(N, V_{E, c}\right)$ is superadditive. Let $S, T \in 2^{N} \backslash\{\emptyset\}$ with $S \cap T \neq \emptyset$. Let $x \in \mathbb{R}^{N}$ with $x_{S} \in V_{E, c}(S)$ and $x_{T} \in V_{E, c}(T)$. We show that $x_{S \cap T} \in V(S \cap T)$ or $x_{S \cup T} \in V(S \cup T)$. Without loss of generality, it suffices to distinguish between two cases: (1) $\left(0_{S}, c_{N \backslash S}\right) \notin E$ and (2) $\left(0_{S}, c_{N \backslash S}\right) \in E$ and $\left(0_{T}, c_{N \backslash T}\right) \in E$.

Case 1: $\left(0_{S}, c_{N \backslash S}\right) \notin E$.

In this case, $\left(0_{S \cap T}, c_{N \backslash(S \cap T)}\right) \notin E$ by condition (E3) of NTU-bankruptcy problems and, consequently,

$$
V_{E, c}(S)=\operatorname{comp}\left(\left\{0_{S}\right\}\right) \text { and } V_{E, c}(S \cap T)=\operatorname{comp}\left(\left\{0_{S \cap T}\right\}\right) .
$$


Then, $x_{S} \leq 0_{S}$ and $x_{S \cap T} \in V_{E, c}(S \cap T)$.

Case 2: $\left(0_{S}, c_{N \backslash S}\right) \in E$ and $\left(0_{T}, c_{N \backslash T}\right) \in E$.

In this case, $\left(0_{S \cup T}, c_{N \backslash(S \cup T)}\right) \in E$ by condition (E3) of NTU-bankruptcy problems and, consequently,

$$
V_{E, c}(R)=\operatorname{comp}\left(\left\{w \in \mathbb{R}^{R}: w \leq c_{R},\left(w, c_{N \backslash R}\right) \in E\right\}\right)
$$

for $R \in\{S, T, S \cup T\}$. First, $x_{T} \in V_{E, c}(T)$ implies $x_{T \backslash S} \leq c_{T \backslash S}$. Second, Lemma 2 implies $\left(x_{S}, c_{T \backslash S}\right) \in V_{E, c}(S \cup T)$ and, therefore, $x_{S \cup T} \in V_{E, c}(S \cup T)$.

We conclude the study of convexity of NTU-bankruptcy games with an example illustrating that NTU-bankruptcy games need not be cardinally convex.

Example 6 Consider the NTU-bankruptcy problem $(N, E, c)$ with $N=\{1,2,3,4\}$, $E=\left\{x \in \mathbb{R}^{N}:\left(x_{1}+x_{3}\right)^{2}+\left(x_{2}+x_{4}\right)^{2} \leq 19\right\}$, and $c=(2,2,2,2)$. Then, $V_{E, c}(\{1\})=\operatorname{comp}\left(\left\{0_{\{1\}}\right\}\right),(\sqrt{15}-2,0) \in V_{E, c}(\{1,2\})$, and $(\sqrt{3}, 0) \in V_{E, c}(\{1,3\})$. As a result $x=(\sqrt{15}-2,0,0,0) \in V_{E, c}^{0}(\{1,2\}), y=(\sqrt{3}, 0,0,0) \in V_{E, c}^{0}(\{1,3\})$, but $x+y=(\sqrt{15}+\sqrt{3}-2,0,0,0) \notin V_{E, c}^{0}(\{1\})+V_{E, c}^{0}(\{1,2,3\})$ since $\bar{x} \in V_{E, c}^{0}(\{1\})$ implies $\bar{x}_{1} \leq 0$ and $\bar{y} \in V_{E, c}^{0}(\{1,2,3\})$ implies $\bar{y}_{1} \leq c_{1}=2$ while $x_{1}+y_{1}>2$.

Next, we show that NTU-bankruptcy games are compromise stable.

Theorem 6 Every NTU-bankruptcy game is compromise stable.

Proof Let $(N, E, c)$ be an NTU-bankruptcy problem and let $\left(N, V_{E, c}\right)$ be the associated NTU-bankruptcy game. By Theorem 2, it suffices to show that either

$$
V_{E, c}(S) \subset\left\{x \in \mathbb{R}^{S}: x \leq k_{S}\left(V_{E, c}\right)\right\}
$$

or

$$
\begin{aligned}
& V_{E, c}(S) \subset \operatorname{comp}\left(\left\{x \in \mathbb{R}^{S}: \text { there exists } y \in \mathrm{WP}\left(V_{E, c}(N)\right) \text { with } y_{S}=x\right.\right. \\
& \text { and } \left.\left.y_{N \backslash S} \geq K_{N \backslash S}\left(V_{E, c}\right)\right\}\right)
\end{aligned}
$$

for every $S \in 2^{N} \backslash\{\emptyset\}$. Fix $S \in 2^{N} \backslash\{\emptyset\}$, we distinguish between two cases: (1) $\left(0_{S}, c_{N \backslash S}\right) \in E$ and $(2)\left(0_{S}, c_{N \backslash S}\right) \notin E$.

Case 1: $\left(0_{S}, c_{N \backslash S}\right) \in E$. 
Then, $\left(0_{N \backslash\{i\}}, c_{i}\right) \in E$ for every $i \in N \backslash S$ by condition (E3) of NTU-bankruptcy problems and, consequently, $c_{N \backslash S}=c_{N \backslash S}^{t}=K_{N \backslash S}\left(V_{E, c}\right)$ by Proposition 1 (ii). Then,

$$
\begin{aligned}
V_{E, c}(S) & =\operatorname{comp}\left(\left\{w \in \mathbb{R}^{S}: w \leq c_{S},\left(w, c_{N \backslash S}\right) \in E\right\}\right) \\
& =\operatorname{comp}\left(\left\{w \in \mathbb{R}^{S}: w \leq c_{S},\left(w, K_{N \backslash S}\left(V_{E, c}\right)\right) \in E\right\}\right) \\
& =\operatorname{comp}\left(\left\{w \in \mathbb{R}^{S}: w \leq c_{S},\left(w, K_{N \backslash S}\left(V_{E, c}\right)\right) \in \operatorname{WP}(E)\right\}\right) \\
& \subset \operatorname{comp}\left(\left\{w \in \mathbb{R}^{S}: \text { there exists } y \in \operatorname{WP}\left(V_{E, c}(N)\right) \text { with } y_{S}=w\right.\right. \\
& \text { and } \left.\left.y_{N \backslash S} \geq K_{N \backslash S}\left(V_{E, c}\right)\right\}\right),
\end{aligned}
$$

where the third equality is a direct consequence of (E3) and (E4).

Case 2: $\left(0_{S}, c_{N \backslash S}\right) \notin E$.

In this case, $\left(0_{\{i\}}, c_{N \backslash\{i\}}\right) \notin E$ for every $i \in S$ by condition (E3) of NTU-bankruptcy problems and $k_{i}\left(V_{E, c}\right)=v_{E, c}(i)=0$ for every $i \in S$, where the first equality follows by Proposition 1 (iii). Moreover, $x \in V_{E, c}(S)$ implies $x \leq 0_{S}$. Therefore, $V_{E, c}(S) \subset\left\{x \in \mathbb{R}^{S}: x \leq k_{S}\left(V_{E, c}\right)\right\}$.

\section{A game theoretical NTU-bankruptcy rule}

The adjusted proportional rule was introduced for TU-bankruptcy problems in Curiel et al. (1987). The adjusted proportional rule assigns to each agent his minimal right first, and the remaining estate is proportionally shared with respect to the vector of updated claims, where the new claim takes into account that every agent has already obtained his minimal right and that nobody should get more than the remaining estate. Formally, given a TU-bankruptcy problem $(N, e, c)$, the adjusted proportional rule assigns

$$
\operatorname{AProp}(N, e, c)=m(N, e, c)+\operatorname{Prop}(N, \tilde{e}, \tilde{c})
$$

where $m_{i}(N, e, c)=\max \left\{0, e-\sum_{j \in N \backslash\{i\}} c_{j}\right\}, \tilde{e}=e-\sum_{i \in N} m_{i}(N, e, c)$, $\tilde{c}_{i}=\min \left\{\tilde{e}, c_{i}-m_{i}(N, e, c)\right\}$, and $\operatorname{Prop}(N, \tilde{e}, \tilde{c})=\frac{\tilde{e}}{\sum_{i \in N} \tilde{c} \tilde{c}_{i}} \tilde{c}$. By definition of TUbankruptcy games, $m_{i}(N, e, c)=v_{e, c}(i)$. Curiel et al. (1987) show that the adjusted proportional rule and the compromise value of the associated TU-bankruptcy game lead to the same allocation for any TU-bankruptcy problem. Next, we show that this result can be generalized to the NTU-setting.

In order to generalize the adjusted proportional rule to NTU-bankruptcy problems, we first need to define the minimal right of an agent in an NTU-bankruptcy problem. Let $(N, E, c)$ be an NTU-bankruptcy problem and let $i \in N$. The minimal right of agent $i, m_{i}(N, E, c)$, is defined by $m_{i}(N, E, c)=v_{E, c}(i)$. Then, for an NTU-bankruptcy problem $(N, E, c)$, the adjusted proportional rule assigns 

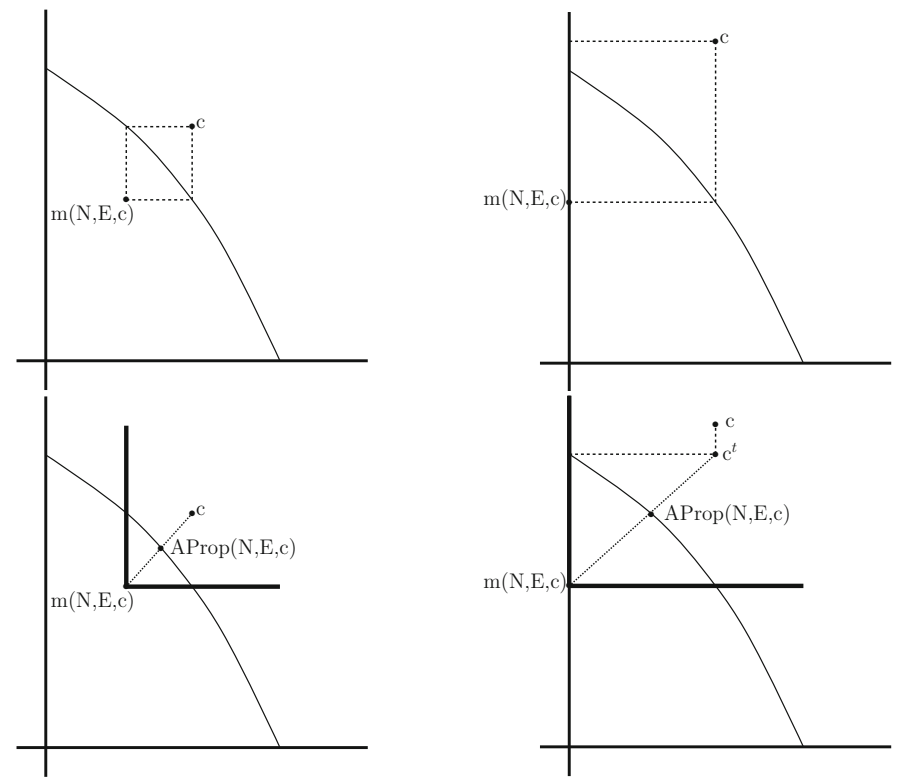

Fig. 2 Graphical illustrations of the adjusted proportional rule

$$
\operatorname{AProp}(N, E, c)=m(N, E, c)+\operatorname{Prop}(N, \tilde{E}, \tilde{c}),
$$

where $\tilde{E}=E-\{m(N, E, c)\}, \tilde{c}=c^{t}-m(N, E, c) \in \mathbb{R}^{N}$, and $\operatorname{Prop}(N, \tilde{E}, \tilde{c})=t \tilde{c}$ with $t=\max \left\{\tilde{t} \in \mathbb{R}_{+}: \tilde{t} \tilde{c} \in \tilde{E}\right\}$. It readily follows that $0 \leq \operatorname{AProp}(N, E, c) \leq c$ (Fig. 2).

Theorem 7 Let $(N, E, c)$ be an NTU-bankruptcy problem. Then,

$$
\operatorname{AProp}(N, E, c)=T\left(V_{E, c}\right) .
$$

Proof We have to show that

$$
\begin{aligned}
\operatorname{AProp}(N, E, c) & =m(N, E, c)+\operatorname{Prop}(N, \tilde{E}, \tilde{c}) \\
& =\lambda K\left(V_{E, c}\right)+(1-\lambda) k\left(V_{E, c}\right)=T\left(V_{E, c}\right)
\end{aligned}
$$

with $\tilde{E}=E-\{m(N, E, c)\}, \tilde{c}=c^{t}-m(N, E, c)$, and $\lambda=\max \{\tilde{\lambda} \in[0,1]: \tilde{\lambda} K$ $\left.\left(V_{E, c}\right)+(1-\tilde{\lambda}) k\left(V_{E, c}\right) \in V_{E, c}(N)\right\}$. By Proposition $1, m(N, E, c)=\left(v_{E, c}(i)\right)_{i \in N}=$ $k\left(V_{E, c}\right)$. Moreover,

$$
T\left(V_{E, c}\right)=k\left(V_{E, c}\right)+\lambda\left(K\left(V_{E, c}\right)-k\left(V_{E, c}\right)\right) .
$$

Therefore, it suffices to show that

$$
\operatorname{Prop}(N, \tilde{E}, \tilde{c})=\lambda\left(K\left(V_{E, c}\right)-k\left(V_{E, c}\right)\right) .
$$


By Proposition $1, K\left(V_{E, c}\right)=c^{t}$. Then,

$$
\operatorname{Prop}(N, \tilde{E}, \tilde{c})=t \tilde{c}=t\left(c^{t}-m(N, E, c)\right)=t\left(K\left(V_{E, c}\right)-k\left(V_{E, c}\right)\right),
$$

where $t=\max \left\{\tilde{t} \in \mathbb{R}_{+}: \tilde{t} \tilde{c} \in \tilde{E}\right\}$. Therefore, we only need to show that $t=\lambda$. It follows that

$$
\begin{aligned}
t & =\max \left\{\tilde{t} \in \mathbb{R}_{+}: \tilde{t} \tilde{c} \in \tilde{E}\right\} \\
& =\max \left\{\tilde{t} \in \mathbb{R}_{+}: \tilde{t}\left(c^{t}-m(N, E, c)\right) \in(E-\{m(N, E, c)\})\right\} \\
& =\max \left\{\tilde{t} \in \mathbb{R}_{+}: \tilde{t}\left(K\left(V_{E, c}\right)-k\left(V_{E, c}\right)\right) \in\left(V_{E, c}(N)-\left\{k\left(V_{E, c}\right)\right\}\right)\right\} \\
& =\max \left\{\tilde{t} \in \mathbb{R}_{+}: k\left(V_{E, c}\right)+\tilde{t}\left(K\left(V_{E, c}\right)-k\left(V_{E, c}\right)\right) \in V_{E, c}(N)\right\} \\
& =\max \left\{\tilde{t} \in[0,1]: k\left(V_{E, c}\right)+\tilde{t}\left(K\left(V_{E, c}\right)-k\left(V_{E, c}\right)\right) \in V_{E, c}(N)\right\} \\
& =\max \left\{\tilde{t} \in[0,1]: \tilde{t} K\left(V_{E, c}\right)+(1-\tilde{t}) k\left(V_{E, c}\right) \in V_{E, c}(N)\right\}=\lambda,
\end{aligned}
$$

where the second equality follows by definition of $\tilde{c}$ and $\tilde{E}$; the third equality is a direct consequence of $K\left(V_{E, c}\right)=c^{t}, k\left(V_{E, c}\right)=m(N, E, c)$, and $V_{E, c}(N)=\operatorname{comp}(E)$; the fifth equality follows because $k\left(V_{E, c}\right)+t\left(K\left(V_{E, c}\right)-k\left(V_{E, c}\right)\right)$ is the unique vector on the line segment between $k\left(V_{E, c}\right)$ and $K\left(V_{E, c}\right)$ which lies in $V_{E, c}(N)$ and is closest to $K\left(V_{E, c}\right)$.

Acknowledgements The authors thank two referees for their valuable suggestions for improvement. Special thanks go to Bas Dietzenbacher for his helpful comments.

Open Access This article is distributed under the terms of the Creative Commons Attribution 4.0 International License (http://creativecommons.org/licenses/by/4.0/), which permits unrestricted use, distribution, and reproduction in any medium, provided you give appropriate credit to the original author(s) and the source, provide a link to the Creative Commons license, and indicate if changes were made.

\section{References}

Aumann RJ (1985) An axiomatization of the non-transferable utility value. Econometrica 53:599-612

Aumann R, Maschler M (1985) Game theoretic analysis of a bankruptcy problem from the talmud. J Econ Theory 36:195-213

Borm P, Keiding H, McLean RP, Oortwijn S, Tijs S (1992) The compromise value for NTU-games. Int J Game Theory 21:175-189

Chun Y, Thomson W (1992) Bargaining problems with claims. Math Soc Sci 24:19-33

Csóka P, Herings P, Kóczy L, Pintér M (2011) Convex and exact games with non-transferable utility. Eur J Oper Res 209:57-62

Curiel IJ, Maschler M, Tijs S (1987) Bankruptcy games. Z Oper Res 31:A 143-A 159

Dietzenbacher BJ (2018) Bankruptcy games with nontransferable utility. Math Soc Sci 92:16-21

Estévez-Fernández A, Fiestras-Janeiro MG, Mosquera MA, Sánchez E (2012) A bankruptcy approach to the core cover. Math Methods Oper Res 76:343-359

Fragnelli V, Gastaldi F (2017) Remarks on the integer Talmud solution for integer bankruptcy problems. TOP 25:127-163

Fragnelli V, Gagliardo S, Gastaldi F (2014) Integer solutions to bankruptcy problems with non-integer claims. TOP 22:892-933

Fragnelli V, Gagliardo S, Gastaldi F (2016) Bankruptcy problems with non-integer claims: definition and characterizations of the ICEA solution. TOP 24:88-130 
Greenberg J (1985) Cores of convex games without side payments. Math Oper Res 10:523-525

Hendrickx R, Borm P, Timmer J (2002) A note on NTU convexity. Int J Game Theory 31:29-37

Herrero C, Martínez R (2008) Ballanced allocation methods for claims problems with indivisibilities. Soc Choice Welf 30:603-617

O’Neill B (1982) A problem of rights arbitration from the talmud. Math Soc Sci 2:345-371

Orshan G, Valenciano F, Zarzuelo JM (2003) The bilateral consistent prekernel, the core, and NTU bankruptcy problems. Math Oper Res 28:268-282

Peleg B, Sudhölter P (2007) Introduction to the theory of cooperative games, vol 34. Springer, Berlin

Predtetchinski A, Herings P (2004) A necessary and sufficient condition for the non-emptiness of the core of a non-transferable utility game. J Econ Theory 116:84-92

Quant M, Borm P, Reijnierse H, van Velzen B (2005) The core cover in relation to the nucleolus and the Weber set. Int J Game Theory 33:491-503

Shapley LS (1971) Cores of convex games. Int J Game Theory 1:11-26

Sharkey WW (1981) Convex games without side payments. Int J Game Theory 10:101-106

Thomson W (2003) Axiomatic and game-theoretic analysis of bankruptcy and taxation problems: a survey. Math Soc Sci 45:249-297

Thomson W (2015) Axiomatic and game-theoretic analysis of bankruptcy and taxation problems: an update. Math Soc Sci 74:867-880

Tijs SH (1981) Bounds for the core and the $\tau$-value. In: Moeschlin O, Pallaschke D (eds) Game Theory and Mathematical Economics. North-Holland, Amsterdam, pp 123-132

Tijs SH, Lipperts F (1982) The hypercube and the core cover of $n$-person cooperative games. Cahiers du Centre d'Études de Researche Opérationelle 24:27-37

Vidal-Puga J (2008) Forming coalitions and the Shapley NTU value. Eur J Oper Res 190:659-671

Vilkov V (1977) Convex games without side payments. Vestnik Leningradskiva Universitata 7:21-24 (In Russian)

Weber RJ (1988) Probabilistic values for games. In: Roth AE (ed) The Shapley value: essays in honor of Lloyd S Shapley. Cambridge University Press, Cambridge, pp 101-119

Publisher's Note Springer Nature remains neutral with regard to jurisdictional claims in published maps and institutional affiliations. 